\title{
Article \\ Functional Responses and Additive Multiple Predator Effects of Two Common Wetland Fish
}

\author{
Linton F. Munyai ${ }^{1, *(\mathbb{D})}$, Tatenda Dalu ${ }^{2,3, * \mathbb{D}}$, Ryan J. Wasserman ${ }^{3,4}$, Lutendo Mugwedi ${ }^{1}$, Farai Dondofema ${ }^{1}$, \\ ${\text { Gordon } \mathrm{O}^{\prime} \text { Brien }}^{2}(\mathrm{D})$ and Ross N. Cuthbert ${ }^{3,5}$ (D)
}

check for

updates

Citation: Munyai, L.F.; Dalu, T.;

Wasserman, R.J.; Mugwedi, L.;

Dondofema, F.; O'Brien, G.; Cuthbert, R.N. Functional Responses and Additive Multiple Predator Effects of Two Common Wetland Fish. Water 2022, 14, 699. https://doi.org/ 10.3390/w14050699

Academic Editors: Eva

Papastergiadou and Kostas Stefanidis

Received: 22 January 2022

Accepted: 21 February 2022

Published: 23 February 2022

Publisher's Note: MDPI stays neutral with regard to jurisdictional claims in published maps and institutional affiliations.

Copyright: (C) 2022 by the authors. Licensee MDPI, Basel, Switzerland. This article is an open access article distributed under the terms and conditions of the Creative Commons Attribution (CC BY) license (https:/ / creativecommons.org/licenses/by/ $4.0 /)$.
1 Aquatic Systems Research Group, Department of Geography and Environmental Sciences, University of Venda, Thohoyandou 0950, South Africa; lutendo.mugwedi@univen.ac.za (L.M.); farai.dondofema@univen.ac.za (F.D.)

2 School of Biology and Environmental Sciences, University of Mpumalanga, Nelspruit 1200, South Africa; gordon.obrien@ump.ac.za

3 South African Institute for Aquatic Biodiversity, Makhanda 6140, South Africa; r.wasserman@ru.ac.za (R.J.W.); rossnoelcuthbert@gmail.com (R.N.C.)

4 Department of Zoology and Entomology, Rhodes University, Makhanda 6140, South Africa

5 GEOMAR Helmholtz-Zentrum für Ozeanforschung Kiel, 24105 Kiel, Germany

* Correspondence: munyailinton@gmail.com (L.F.M.); dalutatenda@yahoo.co.uk (T.D.)

\begin{abstract}
Understanding trophic interactions is essential for the prediction and measurement of structure and function in aquatic environments. Communities in these ecosystems may be shaped by variables such as predator diversity, prey density and emergent multiple predator effects (MPEs), which are likely to influence trophic dynamics. In this study, we examined the effect of key predatory fish in floodplain wetlands, namely Oreochromis mossambicus and Enteromius paludinosus, towards Chironomidae prey, using a comparative functional response (FR) approach. We used single predator species as well as intra- and interspecific paired species to contrast FRs under multiple predator scenarios. Attack rate and handling time estimates from single predator FRs were used to predict multiple predators' feeding rates, which were compared to observe multiple predators' feeding rates to quantify potential MPEs. From single fish trials, each species displayed a significant Type II FR, characterized by high feeding rates at low prey densities. Oreochromis mossambicus had a steeper (initial slope, i.e., higher attack rate) and higher (asymptote of curve, i.e., shorter handling time and higher maximum feeding rate) FR, whereas E. paludinosus exhibited lower-magnitude FRs (i.e., lower attack rate, longer handling time and lower feeding rate). In multiple predator scenarios, feeding rates were well-predicted by those of single predators, both in conspecific and interspecific pairs, and thus we did not find evidence for antagonistic or synergistic MPEs. Predator-prey interactions in wetland systems can have significant consequences on the structure and dynamics of ecological communities. In turn, this could have destabilizing effects on resources in tropical wetlands. These results, although experimental, help us understand how trophic interaction among conspecific or interspecific fish species in Austral tropical wetlands might influence their aquatic prey species. This will help us to understand food web dynamics better.
\end{abstract}

Keywords: consumer-resource dynamics; feeding rates; Oreochromis mossambicus; Enteromius paludinosus; predator-prey dynamics; prey risk

\section{Introduction}

Predator-prey dynamics are central to our understanding of how species interact and are pervasive determinants of community structure [1,2]. However, these dynamics in tropical and subtropical wetlands systems have received little scientific interest [3,4]. In most tropical and subtropical regions, wetland environments are widespread and highly diverse, representing a myriad of systems ranging from permanent to ephemeral $[5,6]$. Floodplain wetlands are especially common in tropical and subtropical regions and are 
characterized by seasonal rainfall [7]. Unlike most endorheic systems, floodplain connection to permanent water typically facilitates small-bodied fish presence in their food webs during their hydroperiod [8]. In these shallow systems, small-bodied fish typically represent the top of the aquatic food web, often exploiting the rich productivity associated with wetlands during the wet season $[9,10]$. Multiple predatory species exploit these environments, but little is known on how predator-predator interactions may facilitate or disrupt predatorprey dynamics.

Trophic interactions and food webs are characterized by trait-(non-consumptive) and density-mediated (consumptive) processes, with the former particularly pervasive in aquatic environments due to the presence of water-borne cues [11,12]. Although consideration of both processes is crucial for a holistic understanding of trophic dynamics, most attention has been directed at density-mediated effects. One way in which trait-mediated effects can manifest is through so-called multiple predator effects (MPEs). Most communities are comprised of more than one predator, with predator-predator interactions potentially resulting in altered prey risk [13]. There are three forms in which predator-predator interactions classically manifest, and these include (i) additive, where predators interact independently with their prey irrespective of predator density, and thus multiple predator feeding rates are predictable based on individuals (i.e., a lack of MPE); (ii) antagonistic MPEs, where predator-predator interference reduces impact and thus alleviates prey risk; and (iii) synergistic MPEs, where interactions enhance predatory impacts and, therefore, increase prey risk $[1,14]$.

Functional response quantification is a classical approach in determining consumerresource dynamics in ecosystems. Functional responses describe consumption rates (e.g., by predators) as a function of resource density (e.g., prey) [15,16]. In doing so, FRs can inform whether the consumer will have the ability to regulate, stabilize or de-stabilize the resource (prey) populations, with implications for population viability in an ecosystem [17]. Several studies (e.g., [18-20]) have used FRs to understand predator-prey interactions. The significance of floodplain fish and their interaction with the natural aquatic ecosystem is less well understood than in other inland wetland habitats. Even though human modifications are well-known to have significantly altered fish community structures and reduced their diversity [21,22], floodplains continue to support diverse fish assemblages and provide an important habitat for many fish species [23]. Furthermore, available data on floodplains habitat and wetland fish assemblages and interactions are still quite limited and much information on the basic ecology of wetland fish associated with these habitats is less studied.

Functional responses have also been used in MPE frameworks, because predation risk from multiple predators may also be inherently influenced by prey density [24,25]. For example, studies by $[1,14,25]$ reported that the MPE sign and strength differed with prey density and that the influence of prey density varied for different prey species. Specifically, at low prey densities, all prey are typically extirpated in non-prey replacement experimental designs, and thus there is little capacity to detect non-trophic interactions (e.g., interference between predator individuals). At intermediate prey densities, competition between predators for limited resources is high, resulting in antagonisms. Conversely, at high prey densities, prey are abundant and thus not extirpated, with predator-predator interactions, and thus MPEs, potentially less pertinent [26].

The use of such an approach for floodplain wetland fauna could thus link the densitydependent dynamics of predator and prey populations [27] and help to understand direct and indirect food-web interactions [28,29] among key individuals (such as macroinvertebrates, freshwater fish and plants) in these systems. Previous studies on predator-prey interactions have mostly focused on MPE relationships between macroinvertebrate predators and their prey $[30,31]$, however, higher trophic levels have lacked extensive examination (but see Wasserman et al. [32] and Mofu et al. [33]). In floodplain wetlands, fish predation is a major pressure on invertebrate prey, particularly during seasons where large numbers of small bodies and young fish species are prevalent. Determining the strength of per capita 
interactions, and predator-predator dynamics, from these fish is thus fundamental for informing comprehensive floodplain wetland food web modelling, providing valuable information on top-down control dynamics in these systems.

This study thus aimed to assess the feeding interactions of the native Mozambique tilapia (Oreochromis mossambicus) and straight-fin barb (Enteromius paludinosus), towards a readily consumed prey (Chironomidae), under multi-predator scenarios using the comparative FR approach. We sought to examine the potential importance of conspecific and interspecific interaction dynamics for the nature and strength of MPEs towards prey, across a range of prey densities. Oreochromis mossambicus and E. paludinosus have both been found to be among the most common fish species present in tropical floodplain wetlands systems $[34,35]$. We predicted that $O$. mossambicus would likely be more efficient at finding prey at low densities (i.e., higher attack rate) and would have a higher feeding rate throughout than E. paludinosus, given that the former is more carnivorous when they are juveniles, while the latter is omnivorous [36,37]. This prediction is supported by the evidence from a previous study which proved that $O$. mossambicus resembles a higher attack rate compared to E. paludinosus [38]. We also predicted that interspecific MPEs would be more pronounced than conspecific through interference, since interspecific combination resembles a high consumption rate towards their prey due to competition in the given ecosystem.

\section{Materials and Methods}

\subsection{Animal Collection}

In December 2020, experiments were performed in the Pollution Laboratory Atrium at the University of Venda, South Africa. Juvenile Oreochromis mossambicus and Enteromius paludinosus were collected from local wetland systems around Thohoyandou (i.e., Tshifulanani $(-23.041668 ; 30.400553)$ and Duthuni $(-22.965715 ; 30.395720))$. Fish were captured using a 30-metre seine net (mesh $0.5 \mathrm{~cm}$ ) and transported in $25 \mathrm{~L}$ plastic containers filled with source water to the laboratory. The two species were kept separately in $4 \times 25 \mathrm{~L}$ open buckets with 10 fishes being placed per bucket in borehole/wetland (50:50) water. All fish were acclimatized and starved for $48 \mathrm{~h}$ prior to experiments at $26 \pm 1.5^{\circ} \mathrm{C}$. This temperature was chosen based on the recorded temperature of water where fish were collected. Experiments were conducted in individual $10 \mathrm{~L}$ polyethylene buckets (navy-blue; $20 \mathrm{~cm}$ diameter at the base, $24 \mathrm{~cm}$ high) containing $6 \mathrm{~L}$ of borehole/wetland (50:50) water. All fish used in the experiment were size-matched according to total length (TL) $(O$. mossambicus (mean $\pm \mathrm{SD}$ ) $=6.4 \pm 0.3 \mathrm{~cm} \mathrm{TL}$; E. paludinosus $=6.9 \pm 0.3 \mathrm{~cm} \mathrm{TL}$ ), ensuring no substantial differences in total length between species that might affect feeding rates. Four hours prior to the experiment, random fish of each species were collected from the $25 \mathrm{~L}$ buckets and transferred individually and in conspecific/heterospecific combinations into experimental arenas (navy-blue plastic buckets; $20 \mathrm{~cm}$ diameter at the base, $24 \mathrm{~cm}$ high, containing $9 \mathrm{~L}$ borehole/wetland (50:50)) for further acclimatization to experimental arenas in a randomized array.

\subsection{Experimental Design}

The experimental treatments were (1) O. mossambicus, (2) E. paludinosus, (3) O. mossambicus + O. mossambicus, (4) E. paludinosus + E. paludinosus, (5) O. mossambicus + E. paludinosus (Figure 1). During the FR experiment, dead whole prey (Chironomidae (mean $\pm \mathrm{SD})=$ $10 \pm 1.4 \mathrm{~mm}$; Aquav freeze-dried bloodworms-AQUAV (Xiamen Mincheng Imp and Exp Co., Ltd, Beijing, China), were used for all predator treatments. Previous studies have also used dead prey to quantify trophic interaction strengths (e.g., Boets et al. [39]. For each treatment, six prey densities were used, i.e., 2, 4, 8, 16, 32 and 64 , consisting of four to six randomized replicates per each fish group (i.e., 5 fish treatments $\times 6$ prey densities $\times 4-6$ replicates). Prey were transferred to the buckets with fish inside and after four $h$ of feeding (12:00 to 16:00), fish were removed from the experimental arenas and the total number of prey remaining enumerated. Conspecific and interspecific pairs were treated as two individuals in one arena (bucket) consuming supplied prey, i.e., as a single predatory 
unit (Figure 1). In all replicates conducted, fish were only used once. No predators were added for controls ( $n=5$ per prey density, where $n$ is the sample size that quantify prey consumption). After the experiments, all the fish used for experiments were euthanized humanely following recommendations by Weyl et al. [40] and discarded as a biohazard, as stipulated in our approved animal ethics application.

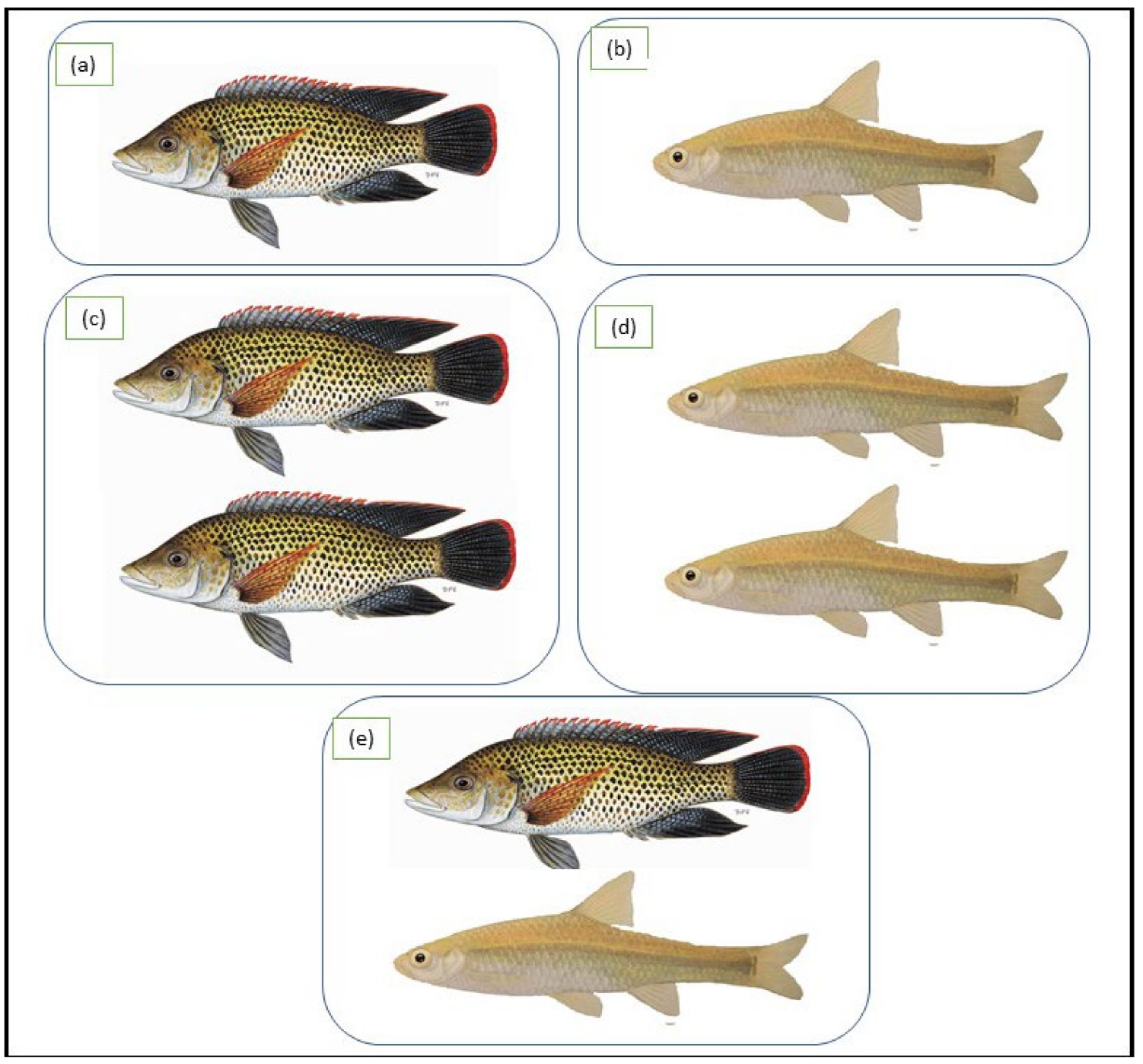

Figure 1. Experimental predator treatments comprising individual predator, conspecific and interspecific pairs of (a) Oreochromis mossambicus; (b) Enteromius paludinosus; (c) Oreochromis mossambicus + Oreochromis mossambicus; (d) Enteromius paludinosus + Enteromius paludinosus; (e) Oreochromis mossambicus + Enteromius paludinosus.

\subsection{Data Analysis}

Differences in proportional feeding rates were examined using a generalized linear model assuming a quasi-binomial error distribution, given residual deviances exceeded degrees of freedom. Predator treatment (five levels) was included as a predictor variable, alongside prey supply (continuous). The interaction term between these factors was not included. Analysis of deviance was used to compute F-tests for the resulting model. Tukey comparisons were used post-hoc for pairwise comparisons of predator treatments [41].

Binomial generalized linear models were additionally used to categorize FR types for both predator treatments at the single predator density [42,43]. A Type II FR was indicated through the presence of a significantly negative linear coefficient in response to increasing prey density, while a Type III functional response would be indicated by a 
significant positive first-order term and significant negative second-order term. Given that the prey were not replaced following consumption over the course of the experiment, Rogers' random predator equation was used to model FRs [44]:

$$
N_{e}=N_{0}\left(1-\exp \left(a\left(N_{e} h-T\right)\right)\right)
$$

where $N_{e}$ is the number of prey eaten, $N_{0}$ is the initial density of prey, $a$ is the attack constant, $h$ is the handling time and $T$ is the total experimental period. The Lambert $\mathrm{W}$ function was used to fit the model to the data $[43,45]$. The random predator equation is robust to prey depletion in parameter estimation [46].

We then used the attack rate and handling time estimates from single predator FRs (1) to predict multiple predators feeding rates, which were next compared to observed multiple predators feeding rates. This was completed separately for multiple predator groups (i.e., $\mathrm{Om}+\mathrm{Om}, \mathrm{Ep}+\mathrm{Ep}$ and $\mathrm{Om}+\mathrm{Ep}$ ) using the corresponding single predator FR parameters. Estimations of $\mathrm{IS}_{\mathrm{T}}$ (i.e., predicted interactions) were calculated following McCoy et al. [24] and Sentis and Boukal [25]:

$$
\frac{d N}{d t}=-\sum_{i=1}^{n} f_{i}(N) P_{i}
$$

where $N$ is the prey population density, $\operatorname{Pi}(i=1,2, \ldots, n)$ are the population densities of predators $i$, and $f_{i}(N)$ is the functional response of predator $i$ (i.e., Equation (1)). This model assumes no emergent MPEs and its predictions can be compared to multiple predators feeding trials to assess the sign and strength of MPEs. To generate predictions of expected prey survival in the multi-predator experiments, initial values of $N$ and $P$ are set at the experimental initial prey and predator densities corresponding to the experimental treatment. For each predator treatment and prey density, Equation (2) was integrated over the full experimental time to obtain the expected numbers of surviving prey. To estimate the variance around the predictions, we used a global sensitivity analysis that uses the 95\% confidence intervals of each FR parameter estimate and their variance-covariance matrix (covariance is assumed to be zero when unknown) to generate 100 random parameter sets using a Latin hypercube sampling algorithm [47]. For each parameter set $(n=100)$, Equation (2) was then integrated over time and expected prey survival was calculated using the 'sensRange' function in the R package 'FME' [47]. We thus compared the confidence intervals between predicted and observed FRs to discern differences (i.e., multiple predator effects) across prey densities. All statistical analyses were performed in R v4.0.2 [48].

\section{Results}

Consumption rates differed significantly among predator treatments $\left(F_{4128}=8.937\right.$, $p<0.001$ ). Single $O$. mossambicus consumed generally a greater proportion of available prey than single E. paludinosus, but this was not significantly different (Tukey test, $p=0.093$ ). However, conspecific pairs of $O$. mossambicus consumed significantly more than conspecific pairs of E. paludinosus (Tukey test, $p<0.001$ ). In turn, interspecific pairs of O. mossambicus and E. paludinosus consumed significantly more prey than conspecific pairs of E. paludinosus $(p=0.026)$, but not conspecific pairs of O. mossambicus (Tukey test, $p=0.895$ ) (Figure 2 ). The rate of prey consumption related significantly negatively with prey supply overall $\left(F_{1128}=146.239, p<0.001\right)$ (Figure 2$)$. 


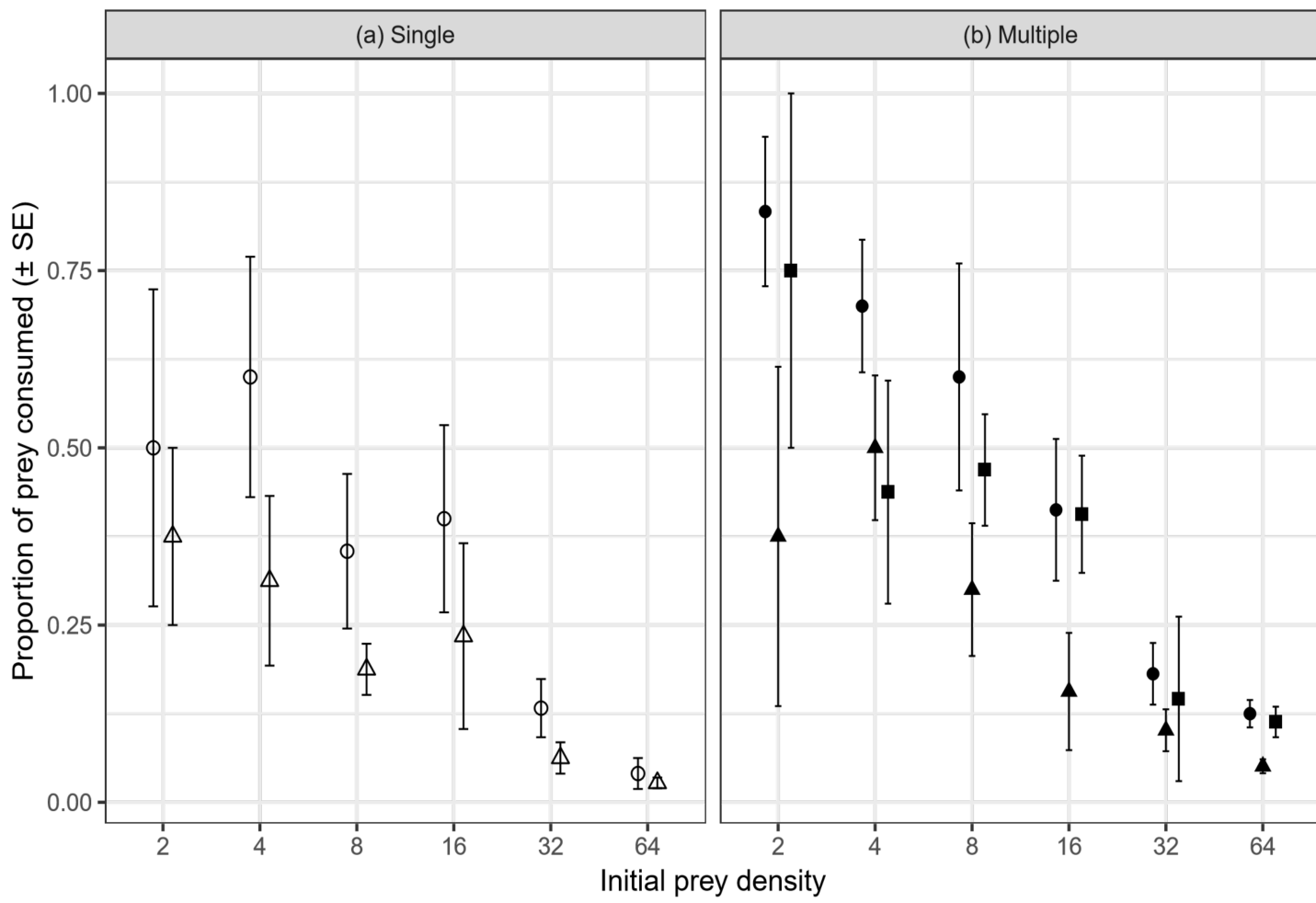

Predator treatment

o Om

$\triangle E p$

- Om+Om

\ $\mathrm{Ep}+\mathrm{Ep}$

- Om+Ep

Figure 2. Mean $( \pm \mathrm{SE})$ proportions of prey consumed by single (a) and multiple (b) predator groups according to predator treatment and prey density. Om = Oreochromis mossambicus, Ep = Enteromius paludinosus

Type II FRs were evidenced by both fish species given significantly negative linear coefficients considering feeding rates as a function of prey density (O. mossambicus: estimate $=-0.054, p<0.001 ;$ E. paludinosus: estimate $=-0.048, p<0001)$. Considering single predators, attack rates of $O$. mossambicus $(a=1.490, p=0.001, \mathrm{SE}=0.456)$ were higher than $E$. paludinosus $(a=0.794 ; p=0.058, \mathrm{SE}=0.418)$, reflecting a steeper FRs slope at low densities (Figure 3a). Handling times of O. mossambicus $(h=0.207, p<0.001, \mathrm{SE}=0.029)$ were also shorter than E. paludinosus $(h=0.377, p<0.001, \mathrm{SE}=0.082)$ and, therefore, $O$. mossambicus had a substantially greater maximum feeding rate over the experimental duration $(1 / h=4.842)$ than did E. paludinosus $(1 / h=2.653)$ (Figure $3 a)$. As such, the asymptote of the functional response for O. mossambicus was substantially higher. However, confidence intervals of FRs overlapped across all prey densities in the single predator groups (Figure 3a).

Considering multiple predator FRs, predicted feeding rates of conspecific O. mossambicus exceeded those observed, however, confidence intervals overlapped at all prey densities (Figure 3b). Likewise, for E. paludinosus, predictions generally exceeded observed FRs, but confidence intervals again overlapped across prey densities (Figure 3c). For interspecific predator pairs, predicted FRs tracked more closely with the experimental observations (Figure 3d). Accordingly, we did not find significant statistical evidence for MPEs in any of the multiple predator groupings, with predation rates generally combining additively between fishes. However, interspecific groupings tended to exhibit the highest predictability (i.e., fewest non-trophic interactions between predators that influence feeding rates). 


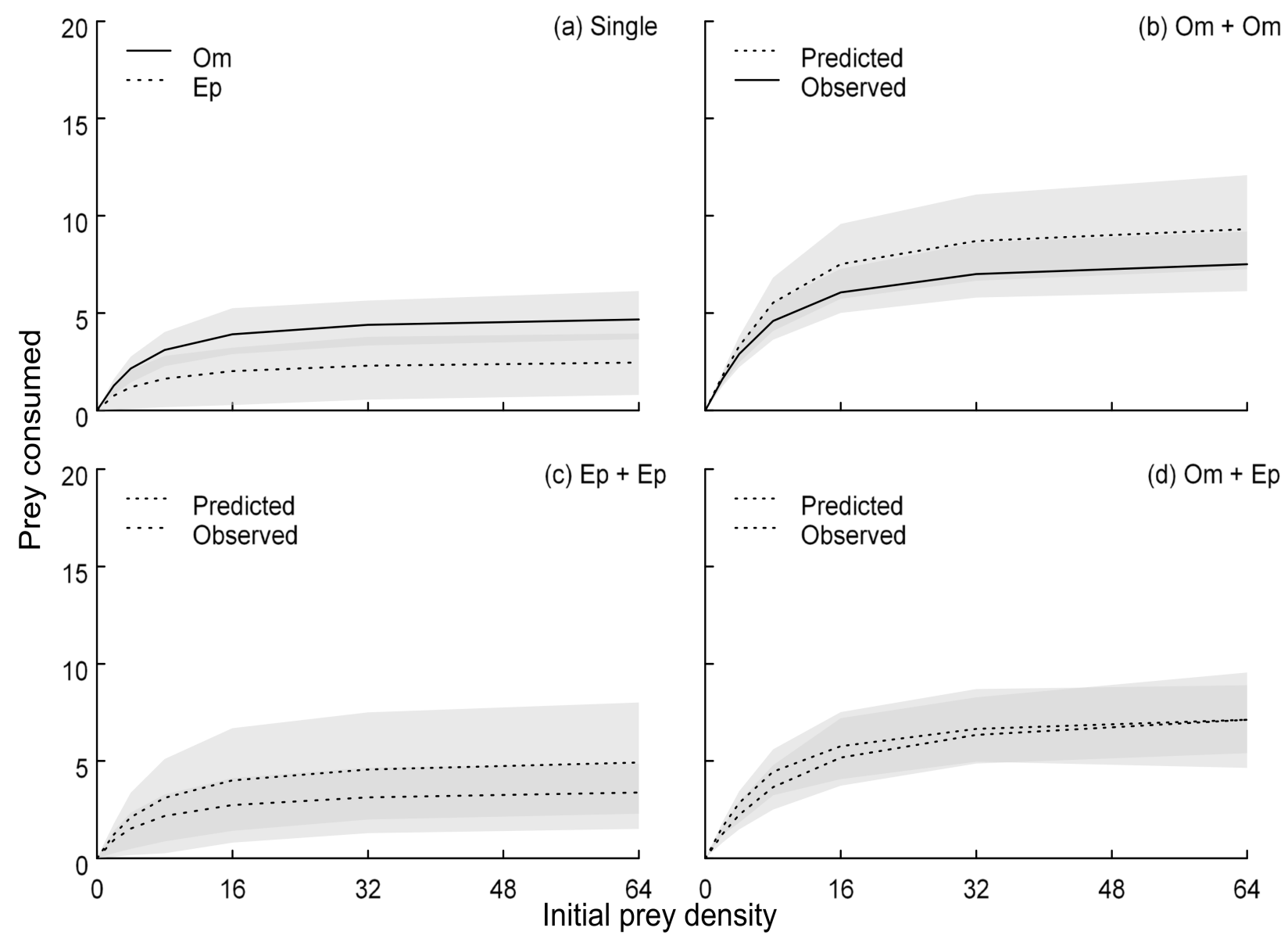

Figure 3. Functional responses of Oreochromis mossambicus (Om) and Enteromius paludinosus (Ep). As single predators (a) and in pairs ( $\mathbf{b}-\mathbf{d})$. Observations correspond to experimental data from paired predator groups, whilst predictions in each panel were modelled from functional responses in single predator groups (a) using a population dynamic approach. Shaded areas are 95\% confidence intervals.

\section{Discussion}

In this study, we combined experiments and modelling to assess potential MPEs between two common and often sympatric species in floodplain wetlands. In predator-prey interactions with single predators, the predictions that E. paludinosus would have higher FR and likely to be more efficient at finding prey at low densities than O. mossambicus were not supported. The two fish species both displayed potentially destabilizing consumption rates individually (Type II FRs) [49], with O. mossambicus generally exhibiting a higher maximum feeding rates and attack rates than E. paludinosus. Our results revealed that, for conspecific interactions, feeding rates combined additively across prey density treatments since expected proportions of prey were consumed relative to those upscaled from single predators. Furthermore, feeding rates originating from interspecific groups of $O$. mossambicus and E. paludinosus combined additively, thus again resulting in an absence of MPEs. Given the important role of predation in the structuring and functioning of aquatic systems [50,51], understanding the implications of predator-prey dynamics is critical for robust interaction strength quantifications between trophic levels; here we found that key wetland fishes display additive feeding interactions.

The study suggests that both O. mossambicus and E. paludinosus could destabilize prey populations, given the high consumption rates at low densities under laboratory conditions. However, the FR results also showed that in single fish trials, O. mossambicus did not have significantly higher FRs (shorter handling times and higher maximum feeding rates) than 
E. paludinosus. A growing literature on predator-prey interaction has shown that predation can potentially yield both positive and negative MPEs [33,52] and a number of ways to model MPE has been employed [1,32]. The population dynamic model employed in this study has been shown to be more robust to non-replacement experimental data than other approaches, such as the multiplicative risk model [25]. When we consider Chironomidae predation by O. mossambicus and E. paludinosus, our study showed additive effects for conspecific pairs, and again additive interactions were observed for intraspecific pairs of these species.

In terms of feeding rates, it was observed that the proportion of prey consumed fell significantly as prey densities increased across treatments, with feeding rates at low densities highest (i.e., Type II FR), suggesting that handling time-limited consumption rates at higher prey densities in all predator treatments. The overall proportion of prey consumed by single predators was generally lower compared to that of multiple predators. Enteromius paludinosus also generally exhibited low resource use compared to O. mossambicus. This reduced consumption by E. paludinosus is due to less efficient foraging tactics that lessens attack rates (i.e., behavioral differences related to search efficiency) and also to a longer handling time (i.e., physiological differences) for prey [53]. Enteromius paludinosus exhibited reduced FRs in comparison with O. mossambicus, and this difference was pronounced when comparing intra- and interspecific pairs, whereby conspecific paired O. mossambicus and interspecific fishes were significantly higher than paired E. paludinosus. This study further suggests that combinations of different fish species of the same sizes exhibit limited interference when foraging towards their prey, thus showing particularly minimal predatorpredator interactions. However, Mofu et al. [33] showed that net prey consumption under multiple predator scenarios can be misleading if individual consumption is not catered for. That study employed a similar design to the present one, but showed, using postexperimental gut content analysis, that one species elevated its feeding while the other reduced its feeding, resulting in a net consumption that revealed no MPEs. This has implications for predator competition dynamics, and such a distinction cannot be made by measuring FRs alone (i.e., with prey consumption pooled between predators). This was also previously attested with a study carried out by Labropoulou and Eleftheriou, [54], whereby two pairs of closely related demersal fish were used to determine the foraging efficiency towards single and multiple prey.

Although studies that model multispecies predator-prey interactions remain rare, the presence of additivity greatly simplifies the construction of predictive models [55,56]. This is because simple additivity decreases the need for detailed prior knowledge about all the interactions (both direct and indirect) that can occur between species in predator-prey systems. The findings of this study emphasize the importance of assessing predator-predator interactions, as these offer insights into resource-use differentiation in multiple predator scenarios. The study further supports the direct FR approach by integrating con-interspecific analysis into the FRs procedure when assessing multiple species interactions, instead of focusing solely on a single or interspecific predators without additional interactions. Given the evidence that a change in FRs of individual species may result from MPEs [24], this study further demonstrates how single and multiple predators can cause additive responses in the aquatic system and how intensely they interact with prey within these systems. The present study further indicates that predator-prey interactions are species-specific, as has been repeatedly evidenced in previous studies among taxa and contexts [57,58]; but there has remained a paucity of knowledge of interaction strength in floodplain wetlands in southern Africa [5].

Despite our results, it is important to highlight potential limitations in our approach. Whereas the present study used thawed frozen chironomid larvae during the experiment, we acknowledge that the use of live prey could have yielded different results given potential prey responses to different predator or prey densities. However, this design allowed us to exclude prey behavior and instead exclusively focus on predator-predator effects on the functional response between these wetland fish species. Furthermore, our choice 
of small-sized experimental arenas without habitat complexity could have resulted in confinement effects which may have intensified (or dampened) trophic (i.e., predator-prey) and non-trophic (i.e., predator-predator) interactions [59,60]. Therefore, while caution should be exerted when extrapolating these results to the floodplain wetland context, laboratory experiments can provide useful comparative insights between species, under controlled conditions, to discern interaction strengths in a controlled manner without wider mechanistic interpretations. A lack of non-trophic interactions found in the present study may thus change given greater volumes in empirical ecosystems; but we found no strong evidence for predator-predator interactions here.

In ecological studies, it is fundamental to understand the biotic processes which impact floodplain wetlands ecosystem structure and functioning. Recent studies have recognized the need to examine individual consumer variability within wetland populations [61,62]. Despite the existing data on trophic interaction of single predator-prey dynamics, which is helpful in determining the strength of MPEs, further exploration studies of interspecific and conspecific interaction relationships are critical, especially regarding fish predation, because fish drive top-down cascades and shape the structure and functioning of invertebrate communities, including the presence of Chironomidae in floodplain wetlands. As such, although often transient features of a community, fish cannot be excluded in the examination of factors that contribute to the functional ecology of floodplain wetlands.

\section{Conclusions}

We have observed that changes in prey can alter predator-prey interactions of fish, and this might lead to changes in predator species population dynamics [33], with implications for the broader aquatic ecosystem community structure and functioning [63]. Additionally, integration of habitat complexities based on the species' natural habitat would likely improve the understanding of processes involved in such interactions [64]. Future studies should be conducted focusing on the assessment of MPEs using FR approaches, not only considering predator-prey interactions of native species but also non-native species which increasingly threaten wetland ecosystems [65]. Furthermore, the present study recommends an intensive study which determines the distribution and abundance of O. mossambicus and E. paludinosus that are found in floodplain wetlands. This will strengthen the FR approach and the impacts which are brought by non-native species to floodplain wetlands systems.

Author Contributions: L.F.M.: Investigation, Data curation, Formal analysis, Writing-original draft; T.D.: Conceptualization, Investigation, Methodology, Resources, Data curation, Supervision, Writing-original draft; R.N.C.: Conceptualization, Methodology, Data curation, Formal analysis, Writing-original draft; L.M.: Investigation, Supervision, Writing—review and editing; R.J.W.: Conceptualization, Methodology, Writing, Supervision, Resources-review and editing; F.D.: Investigation, Writing—review and editing; G.O.: Resources, Writing-review, editing and original draft. All authors have read and agreed to the published version of the manuscript.

Funding: We greatly acknowledge the financial support of the University of Venda Niche Grant (SES/20/ERM/03) and NRF Thuthuka Grant (117700). L.F.M. and R.N.C. acknowledge funding from the National Research Foundation Postgraduate Bursary (129098) and the Alexander von Humboldt Foundation, respectively.

Institutional Review Board Statement: The study was conducted in accordance with the Declaration of Helsinki, and approved by the Ethics Committee of the University of Venda Research and Animal Ethics Committee (Ethical clearance number: SES/20/ERM/14/1611).

Data Availability Statement: The datasets generated and/or analyzed during the current study are not publicly available as they are part of larger study that is currently on-going but are available from the corresponding author on reasonable request.

Acknowledgments: We thank Thendo Mutshekwa for assisting with the experiments. 
Conflicts of Interest: All co-authors have seen and agree with the contents of the manuscript and there is no financial interest to report. Thus, all authors have declared that no competing interests exist.

\section{References}

1. Sih, A.; Englund, G.; Wooster, D. Emergent Impacts of Multiple Predators on Prey. Trends Ecol. Evol. 1998, 13, 350-355. [CrossRef]

2. $\quad$ Barrios-O'Neill, D.; Dick, J.T.A.; Ricciardi, A.; MacIsaac, H.J.; Emmerson, M.C. Deep Impact: In Situ Functional Responses Reveal Context-Dependent Interactions between Vertically Migrating Invasive and Native Mesopredators and Shared Prey. Freshw. Biol. 2014, 59, 2194-2203. [CrossRef]

3. Kumar, R. Impacts of Predation by the Copepod, Mesocyclops Pehpeiensis, on Life Table Demographics and Population Dynamics of Four Cladoceran Species: A Comparative Laboratory Study. Zool. Stud. 2009, 48, 738-752.

4. $\quad$ Cuthbert, R.N.; Dalu, T.; Wasserman, R.J.; Sentis, A.; Weyl, O.L.F.; Froneman, P.W.; Callaghan, A.; Dick, J.T.A. Prey and Predator Density-Dependent Interactions under Different Water Volumes. Ecol. Evol. 2021, 11, 6504-6512. [CrossRef]

5. Dalu, T.; Wasserman, R.J. Fundamentals of Tropical Freshwater Wetlands: From Ecology to Conservation Management; Elsevier: Amsterdam, The Netherlands, 2022; ISBN 978-0-12-822362-8. [CrossRef]

6. Daniel, J.; Rooney, R.C. Wetland Hydroperiod Predicts Community Structure, but Not the Magnitude of Cross-Community Congruence. Sci. Rep. 2021, 11, 429. [CrossRef]

7. Sheaves, M.; Johnston, R.; Abrantes, K.; Sheaves, M.; Johnston, R.; Abrantes, K. Fish Fauna of Dry Tropical and Subtropical Estuarine Floodplain Wetlands. Mar. Freshw. Res. 2007, 58, 931-943. [CrossRef]

8. Carvalho, D.A.; Williner, V.; Giri, F.; Vaccari, C.; Collins, P.A.; Carvalho, D.A.; Williner, V.; Giri, F.; Vaccari, C.; Collins, P.A Quantitative Food Webs and Invertebrate Assemblages of a Large River: A Spatiotemporal Approach in Floodplain Shallow Lakes. Mar. Freshw. Res. 2016, 68, 293-307. [CrossRef]

9. Middelburg, J.J. Stable Isotopes Dissect Aquatic Food Webs from the Top to the Bottom. Biogeosciences 2014, 11, 2357-2371. [CrossRef]

10. Rettig, J.E.; Smith, G.R. Relative Strength of Top-down Effects of an Invasive Fish and Bottom-up Effects of Nutrient Addition in a Simple Aquatic Food Web. Environ. Sci. Pollut. Res. 2021, 28, 5845-5853. [CrossRef]

11. Křivan, V.; Schmitz, O.J. Trait and Density Mediated Indirect Interactions in Simple Food Webs. Oikos 2004, 107, 239-250. [CrossRef]

12. Alexander, M.E.; Dick, J.T.A.; O'Connor, N.E. Trait-Mediated Indirect Interactions in a Marine Intertidal System as Quantified by Functional Responses. Oikos 2013, 122, 1521-1531. [CrossRef]

13. Buxton, M.; Cuthbert, R.N.; Dalu, T.; Nyamukondiwa, C.; Wasserman, R.J. Predator Density Modifies Mosquito Regulation in Increasingly Complex Environments. Pest Manag. Sci. 2020, 76, 2079-2086. [CrossRef] [PubMed]

14. Soluk, D.A. Multiple Predator Effects: Predicting Combined Functional Response of Stream Fish and Invertebrate Predators. Ecology 1993, 74, 219-225. [CrossRef]

15. Holling, C.S. Some Characteristics of Simple Types of Predation and Parasitism 1. Can. Entomol. 1959, 91, 385-398. [CrossRef]

16. Holling, C.S. The Components of Predation as Revealed by a Study of Small-Mammal Predation of the European Pine Sawfly 1. Can. Entomol. 1959, 91, 293-320. [CrossRef]

17. Dick, J.T.A.; Alexander, M.E.; Jeschke, J.M.; Ricciardi, A.; MacIsaac, H.J.; Robinson, T.B.; Kumschick, S.; Weyl, O.L.F.; Dunn, A.M.; Hatcher, M.J.; et al. Advancing Impact Prediction and Hypothesis Testing in Invasion Ecology Using a Comparative Functional Response Approach. Biol. Invasions 2014, 16, 735-753. [CrossRef]

18. Holling, C.S. The Functional Response of Invertebrate Predators to Prey Density. Mem. Entomol. Soc. Can. 1966, 98, 5-86. [CrossRef]

19. Abrams, P. The Functional Responses of Adaptive Consumers of Two Resources. Theor. Popul. Biol. 1987, 32, 262-288. [CrossRef]

20. DeLong, J.P. Predator Ecology: Evolutionary Ecology of the Functional Response; Oxford University Press: Oxford, UK, 2021; ISBN 9780192895509. Available online https:/ /books.google.co.za/books?id=ytg9EAAAQBAJ (accessed on 14 December 2021).

21. Hermoso, V.; Clavero, M.; Blanco-Garrido, F.; Prenda, J. Invasive Species and Habitat Degradation in Iberian Streams: An Analysis of Their Role in Freshwater Fish Diversity Loss. Ecol. Appl. 2011, 21, 175-188. [CrossRef]

22. Leitão, R.P.; Zuanon, J.; Mouillot, D.; Leal, C.G.; Hughes, R.M.; Kaufmann, P.R.; Villéger, S.; Pompeu, P.S.; Kasper, D.; de Paula, F.R.; et al. Disentangling the Pathways of Land Use Impacts on the Functional Structure of Fish Assemblages in Amazon Streams. Ecography 2018, 41, 219-232. [CrossRef]

23. Hurd, L.E.; Sousa, R.G.C.; Siqueira-Souza, F.K.; Cooper, G.J.; Kahn, J.R.; Freitas, C.E.C. Amazon Floodplain Fish Communities: Habitat Connectivity and Conservation in a Rapidly Deteriorating Environment. Biol. Conserv. 2016, 195, 118-127. [CrossRef]

24. McCoy, M.W.; Stier, A.C.; Osenberg, C.W. Emergent Effects of Multiple Predators on Prey Survival: The Importance of Depletion and the Functional Response. Ecol. Lett. 2012, 15, 1449-1456. [CrossRef] [PubMed]

25. Sentis, A.; Boukal, D.S. On the Use of Functional Responses to Quantify Emergent Multiple Predator Effects. Sci. Rep. 2018, 8, 11787. [CrossRef] [PubMed]

26. Sentis, A.; Gémard, C.; Jaugeon, B.; Boukal, D.S. Predator Diversity and Environmental Change Modify the Strengths of Trophic and Nontrophic Interactions. Glob. Change Biol. 2017, 23, 2629-2640. [CrossRef] 
27. Alsakaji, H.J.; Kundu, S.; Rihan, F.A. Delay Differential Model of One-Predator Two-Prey System with Monod-Haldane and Holling Type II Functional Responses. Appl. Math. Comput. 2021, 397, 125919. [CrossRef]

28. Calbet, A.; Landry, M.R. Mesozooplankton Influences on the Microbial Food Web: Direct and Indirect Trophic Interactions in the Oligotrophic Open Ocean. Limnol. Oceanogr. 1999, 44, 1370-1380. [CrossRef]

29. Schmitz, O.J.; Suttle, K.B. Effects of Top Predator Species on Direct and Indirect Interactions in a Food Web. Ecology 2001, 82, 2072-2081. [CrossRef]

30. Brooks, A.C.; Gaskell, P.N.; Maltby, L.L. Sublethal Effects and Predator-Prey Interactions: Implications for Ecological Risk Assessment. Environ. Toxicol. Chem. 2009, 28, 2449-2457. [CrossRef]

31. Klecka, J.; Boukal, D.S. Foraging and Vulnerability Traits Modify Predator-Prey Body Mass Allometry: Freshwater Macroinvertebrates as a Case Study. J. Anim. Ecol. 2013, 82, 1031-1041. [CrossRef]

32. Wasserman, R.J.; Alexander, M.E.; Dalu, T.; Ellender, B.R.; Kaiser, H.; Weyl, O.L.F. Using Functional Responses to Quantify Interaction Effects among Predators. Funct. Ecol. 2016, 30, 1988-1998. [CrossRef]

33. Mofu, L.; South, J.; Wasserman, R.J.; Dalu, T.; Woodford, D.J.; Dick, J.T.A.; Weyl, O.L.F. Inter-Specific Differences in Invader and Native Fish Functional Responses Illustrate Neutral Effects on Prey but Superior Invader Competitive Ability. Freshw. Biol. 2019, 64, 1655-1663. [CrossRef]

34. Barson, M.; Nhiwatiwa, T. Influence of Drought and Flooding on the Colonisation of Floodplain Pans by Riverine Fish in the Zimbabwean Lowveld. Afr. J. Aquat. Sci. 2010, 35, 205-208. [CrossRef]

35. Nhiwatiwa, T.; Maseko, Z.; Dalu, T. Fish Communities in Small Subtropical Reservoirs Subject to Extensive Drawdowns, with Focus on the Biology of Enteromius Paludinosus (Peters, 1852) and Clarias Gariepinus (Burchell, 1822). Ecol. Res. 2017, 32, 971-982. [CrossRef]

36. De Moor, I.J.; Bruton, M.N. Atlas of Alien and Translocated Indigenous Aquatic Animals in Southern Africa; National Scientific Programmes Unit: CSIR, 1988. Available online: http:/ / hdl.handle.net/10204/2416 (accessed on 22 December 2021).

37. Mattson, N.S. Trophic Interactions between Two Tropical Omnivorous Fishes, Oreochromis Shiranus and Barbus Paludinosus: Feeding Selectivities and Food Web Responses. Hydrobiologia 1998, 380, 195. [CrossRef]

38. Rapatsa, M.M.; Moyo, N.A.G. The Functional Response of Two Aquatic Predatory Insects and Its Implications for the Biological Control of Coptodon Rendalli Fry. Ecohydrol. Hydrobiol. 2021, 21, 106-113. [CrossRef]

39. Boets, P.; Laverty, C.; Fukuda, S.; Verreycken, H.; Green, K.; Britton, R.J.; Caffrey, J.; Goethals, P.L.M.; Pegg, J.; Médoc, V.; et al Intra- and Intercontinental Variation in the Functional Responses of a High Impact Alien Invasive Fish. Biol. Invasions 2019, 21, 1751-1762. [CrossRef]

40. Weyl, O.L.F.; Pattrick, P.; Ellender, B.R.; Miya, T.; Woodford, D.J.; Bennett, R.H.; Wasserman, R.J.; Äkinen, T.M. Ethical Considerations for Field Research on Fishes. Koedoe Afr. Prot. Area Conserv. Sci. 2016, 58, a1353. [CrossRef]

41. Length, R. Emmeans: Estimated Marginal Means, Aka Least-Squares Means. R Package Version 1.4.8. 2020. Available online: https://cran.r-project.org/web/packages/emmeans/emmeans.pdf (accessed on 27 December 2021).

42. Juliano, S. Non-Linear Curve Fitting: Predation and Functional Response Curve. Des. Anal. Ecol. Exp. 2001, 178-196. [CrossRef]

43. Pritchard, D.W.; Paterson, R.A.; Bovy, H.C.; Barrios-O'Neill, D. FRAIR: An R Package for Fitting and Comparing Consumer. Funct. Responses 2017, 8, 1528-1534.

44. Rogers, D. Random Search and Insect Population Models. J. Anim. Ecol. 1972, 41, 369-383. [CrossRef]

45. Bolker, B.M. Ecological Models and Data in R; Princeton University Press: Vienna, Austria, 2008; ISBN 9781400840908.

46. Cuthbert, R.N.; Wasserman, R.J.; Dalu, T.; Kaiser, H.; Weyl, O.L.F.; Dick, J.T.A.; Sentis, A.; McCoy, M.W.; Alexander, M.E. Influence of Intra- and Interspecific Variation in Predator-Prey Body Size Ratios on Trophic Interaction Strengths. Ecol. Evol. 2020, 10, 5946-5962. [CrossRef] [PubMed]

47. Soetaert, K.; Petzoldt, T. Inverse Modelling, Sensitivity and Monte Carlo Analysis in R Using Package FME. J. Stat. Softw. 2010, 33, 1-28. [CrossRef]

48. R Core Team. R: A Language and Environment for Statistical Computing. R Foundation for Statistical Computing: Vienna, Austria, 2020. Available online: https:/ / www.R-project.org/ (accessed on 27 December 2021).

49. Cuthbert, R.N.; Dalu, T.; Wasserman, R.J.; Callaghan, A.; Weyl, O.L.F.; Dick, J.T.A. Using Functional Responses to Quantify Notonectid Predatory Impacts across Increasingly Complex Environments. Acta Oecologica 2019, 95, 116-119. [CrossRef]

50. Heck, K.L.; Crowder, L.B. Habitat Structure and Predator-Prey Interactions in Vegetated Aquatic Systems. In Habitat Structure: The Physical Arrangement of Objects in Space; Bell, S.S., McCoy, E.D., Mushinsky, H.R., Eds.; Population and Community Biology Series; Springer: Dordrecht, The Netherlands, 1991; pp. 281-299. ISBN 9789401130769.

51. Wasserman, R.J.; Noyon, M.; Avery, T.S.; Froneman, P.W. Trophic Level Stability-Inducing Effects of Predaceous Early Juvenile Fish in an Estuarine Mesocosm Study. PLoS ONE 2013, 8, e61019. [CrossRef]

52. Palacios, M.M.; Malerba, M.E.; McCormick, M.I. Multiple Predator Effects on Juvenile Prey Survival. Oecologia 2018, 188, 417-427. [CrossRef]

53. Metcalfe, N.B.; Huntingford, F.A.; Thorpe, J.E. The Influence of Predation Risk on the Feeding Motivation and Foraging Strategy of Juvenile Atlantic Salmon. Anim. Behav. 1987, 35, 901-911. [CrossRef]

54. Labropoulou, M.; Eleftheriou, A. The Foraging Ecology of Two Pairs of Congeneric Demersal Fish Species: Importance of Morphological Characteristics in Prey Selection. J. Fish Biol. 1997, 50, 324-340. [CrossRef] 
55. Wilbur, H.M.; Fauth, J.E. Experimental Aquatic Food Webs: Interactions between Two Predators and Two Prey. Am. Nat. 1990, 135, 176-204. [CrossRef]

56. Vucetich, J.A.; Hebblewhite, M.; Smith, D.W.; Peterson, R.O. Predicting Prey Population Dynamics from Kill Rate, Predation Rate and Predator-Prey Ratios in Three Wolf-Ungulate Systems. J. Anim. Ecol. 2011, 80, 1236-1245. [CrossRef]

57. Uiterwaal, S.F.; DeLong, J.P. Multiple Factors, Including Arena Size, Shape the Functional Responses of Ladybird Beetles. J. Appl. Ecol. 2018, 55, 2429-2438. [CrossRef]

58. Cuthbert, R.N.; Dalu, T.; Wasserman, R.J.; Weyl, O.L.F.; Froneman, P.W.; Callaghan, A.; Dick, J.T.A. Additive Multiple Predator Effects of Two Specialist Paradiaptomid Copepods towards Larval Mosquitoes. Limnologica 2019, 79, 125727. [CrossRef]

59. Barrios-O'Neill, D.; Dick, J.T.A.; Emmerson, M.C.; Ricciardi, A.; MacIsaac, H.J. Predator-Free Space, Functional Responses and Biological Invasions. Funct. Ecol. 2015, 29, 377-384. [CrossRef]

60. Uiterwaal, S.F.; Lagerstrom, I.T.; Lyon, S.R.; DeLong, J.P. Data Paper: FoRAGE (Functional Responses from Around the Globe in All Ecosystems) Database: A Compilation of Functional Responses for Consumers and Parasitoids. BioRxiv 2018. [CrossRef]

61. Thorp, C.J.; Alexander, M.E.; Vonesh, J.R.; Measey, J. Size-Dependent Functional Response of Xenopus Laevis Feeding on Mosquito Larvae. Peer] 2018, 6, e5813. [CrossRef]

62. Cuthbert, R.N.; Dalu, T.; Wasserman, R.J.; Monaco, C.J.; Callaghan, A.; Weyl, O.L.F.; Dick, J.T.A. Assessing Multiple Predator, Diurnal and Search Area Effects on Predatory Impacts by Ephemeral Wetland Specialist Copepods. Aquat. Ecol. 2020, 54, 181-191. [CrossRef]

63. Escalera-Vázquez, L.H.; Zambrano, L. The Effect of Seasonal Variation in Abiotic Factors on Fish Community Structure in Temporary and Permanent Pools in a Tropical Wetland. Freshw. Biol. 2010, 55, 2557-2569. [CrossRef]

64. Barrios-O'Neill, D.; Kelly, R.; Dick, J.T.A.; Ricciardi, A.; MacIsaac, H.J.; Emmerson, M.C. On the Context-Dependent Scaling of Consumer Feeding Rates. Ecol. Lett. 2016, 19, 668-678. [CrossRef]

65. Yam, R.S.; Huang, K.P.; Hsieh, H.L.; Lin, H.J.; Huang, S.C. An ecosystem-service approach to evaluate the role of non-native species in urbanized wetlands. Int. J. Environ. Res. Public Health 2015, 12, 3926-3943. [CrossRef] 